\title{
Prevention of venous thrombosis with minidose warfarin after joint replacement
}

\author{
C Dale, A Gallus, A Wycherley, S Langlois, \\ D Howie
}

Adelaide University, Adelaide, South Australia C Dale, medical student

Flinders Medical Centre, Adelaide, South Australia 5042, Australia A Gallus, FRACP, director of haemostasis and thrombosis laboratory

A Wycherley, FRACR, director of nuclear medicine

Royal Adelaide Hospital, Adelaide, South Australia $S$ Langlois, FRACR, head of radiology

D Howie, FRACs, professor of orthopaedic surgery and trauma

Correspondence to: Dr A Gallus, Department of Haematology, Flinders Medical Centre, Bedford Park, South Australia 5042, Australia.

BMF 1991;303:224
Without prophylaxis $5-10 \%$ of patients having elective hip replacement develop clinically important venous thrombosis and about 5\% develop symptomatic embolism, which is fatal in up to $0.5 \% .^{1}$ Effective preventive methods exist, but many orthopaedic surgeons do not use them systematically because they tend to be complex, cumbersome, dangerous, or not generally available. ${ }^{1}$ Minidose warfarin (a fixed dose of $1 \mathrm{mg}$ warfarin a day) is simple, seems to be safe, prevents leg vein thrombosis after elective gynaecological surgery, ${ }^{2}$ and prevents subclavian vein thrombosis after central venous line insertion. ${ }^{3}$ We report a pilot study of its use in elective major joint replacement.

\section{Patients, methods, and results}

Forty five patients having elective hip replacement (35 patients) or knee replacement (10) completed the study. Thirty four were excluded because of previous thromboembolism, allergy to contrast medium, aspirin treatment, a potential drug interaction, refusal of consent by patient or surgeon, mild von Willebrand's disease, or insufficient notice of surgery. Venography failed in five patients.

Warfarin $(1 \mathrm{mg} /$ day $)$ was given for a mean of 20 (SD 3 ) days (range 8 to 28 days) before surgery and continued until bilateral ascending venography seven to 10 days after operation. The trial protocol was approved by the relevant clinical investigation committees. Omitting an actively treated control group was justified ethically on the grounds that no prophylaxis was routinely used by orthopaedic surgeons at either hospital, whereas thrombosis detected by routine

Venous thrombosis at routine venography 7-10 days after total hip or knee replacement $(95 \%$ confidence intervals calculated for observed proportions)

\begin{tabular}{|c|c|c|c|c|}
\hline \multirow[b]{2}{*}{$\begin{array}{l}\text { Site of } \\
\text { thrombosis }\end{array}$} & \multicolumn{2}{|c|}{$\begin{array}{l}\text { Present study } \\
\quad(n=45)\end{array}$} & \multicolumn{2}{|c|}{$\begin{array}{l}\text { Historical controls } \\
\text { Flinders Medical Centre } \\
\quad(\mathbf{n}=115)\end{array}$} \\
\hline & No $(\%)$ & $\begin{array}{c}95 \% \\
\text { Confidence } \\
\text { interval }\end{array}$ & No $(\%)$ & $\begin{array}{c}95 \% \\
\text { Confidence } \\
\text { interval }\end{array}$ \\
\hline \multicolumn{5}{|c|}{ Total hip replacement $(n=35)$} \\
\hline Calf & $9(26)$ & 12.5 to $43 \%$ & $58(50)$ & 40 to $60 \%$ \\
\hline Proximal & $11(31)$ & 17 to $49 \%$ & $38(33)$ & 25 to $43 \%$ \\
\hline Total & $14(40)$ & 24 to $58 \%$ & $70(61)$ & 52 to $71 \%$ \\
\hline \multicolumn{5}{|c|}{ Total knee replacement $(n=10)$} \\
\hline Calf & $7(70)$ & 35 to $93 \%$ & & \\
\hline Proximal & $3(30)$ & 7 to $65 \%$ & & \\
\hline Total & $7(70)$ & 35 to $93 \%$ & & \\
\hline
\end{tabular}

venography could then be treated to prevent extension and embolism.

\section{Results}

Patients had a mean age of 70 (SD 9) years (range 52-94 years) and a mean weight of 72 (SD 15) kg (range $44-119 \mathrm{~kg}) ; 31(89 \%)$ hip replacements and three of 10 knee replacements were done under general anaesthesia; 20 (57\%) hips were replaced with cemented prostheses and $24(69 \%)$ replacements were done with a lateral approach. The prothrombin ratio (international normalised ratio) was normal on the day of surgery (one patient with a ratio of 1.7 on the day before surgery remained in the trial after the ratio fel below 1.5 after vitamin $\mathrm{K}$ was given), increased slightly on day 3 but fell on day 7 . Surgical and postoperative bleeding were not excessive. The rate of venous thrombosis was $40 \%$ after hip replacement and $70 \%$ after knee replacement (table).

\section{Discussion}

Our trial was a relatively unambitious pilot study, methodologically handicapped by its lack of randomised controls. Nevertheless, our findings strongly suggest that minidose warfarin cannot be recommended prophylactically in patients having elective major joint replacement.

We chose a cohort study because routine venography after hip replacement discloses a stable rate of thrombosis of about $50 \%$ in untreated patients, ${ }^{1}$ giving us confidence that a pilot study would quickly indicate if a randomised trial would be worth while. In the event, the rate after minidose warfarin was similar to that in previous controls having hip or knee replacement (table). ${ }^{145}$ There was perhaps a trend towards a lower rate of venous thrombosis in the calf, but the rate in proximal veins remained unchanged. In addition, although $95 \%$ confidence intervals for the observed rates of thrombosis remained wide, their lower limits (table) suggest that any prophylactic effect of minidose warfarin that might be demonstrable with a much larger randomised study is unlikely to be impressive.

We thank the radiologists, anaesthetists, orthopaedic surgeons, and ward nursing staff at Flinders Medical Centre and Royal Adelaide Hospital for their help. The study was funded in part by the National Health and Medical Research Council of Australia and the Adelaide Bone and Joint Research Foundation.

1 Gallus AS Anticoagulants in prevention of venous thromboembolism. In: Hirsh J, ed. Antithrombotic therapy. London: Baillière, 1990: 651-84. (Baillière's clinics in haematology, 3 .

2 Poller L, McKernan A, Thomson JM, et al. Fixed minidose warfarin: a new approach to prophylaxis against venous thrombosis after major surgery. $B M \mathcal{J}$ 1987;295:1309-12.

3 Bern MM, Lokich JJ, Wallach SR, et al. Very low doses of warfarin can preven thrombosis in central venous catheters. A randomized prospective trial. Ann Intern Med 1990;112:423-8.

4 Gallus A, Raman K, Darby T. Venous thrombosis after elective hip replacement - the influence of preventive intermittent calf compression and of surgical technique. $B r$ f Surg 1983;70:17-9.

5 McKenna R, Galante J, Bachmann F, et al. Prevention of venous thromboembolism after total knee replacement by high dose aspirin or intermitten calf and thigh compression. $B M \mathcal{F} 1980 ; 280: 514-7$. 